\title{
Reflexos procedimentais do princípio da imparcialidade administrativa
}

rdai.com.br/index.php/rdai/article/view/427

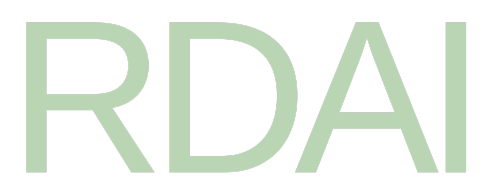

\section{Autores}

David Duarte Universidade de Lisboa (Lisboa, Portugal)

\section{DOI:}

https://doi.org/10.48143/rdai.19.dd

\section{Palavras-chave:}

Imparcialidade, Procedimento administrativo, Instrução, Decisão, Ponderação

\section{Resumo}

O texto analisa como a imparcialidade administrativa, aqui elevada ao patamar de princípio, condiciona a atuação do agente em cada fase do procedimento administrativo que para fins de estudo é dividido em dois centros temáticos, instrução e decisão, com as subdivisões necessárias à concretização de cada uma. A imparcialidade há que estar presente, em especial, na realização de atos internos, antecedentes à divulgação, em momentos instrutórios de levantamento, coleta de informações, inquisitórios e de organização, eis que essa instrumentalização ocasiona a avaliação de interesses a serem ponderados, no que se chama vertente positiva, e afastamento de interesses irrelevantes, vertente negativa, pressupondo a valoração de questões controvertidas. Além das regras de isenção subjetiva, a publicidade dos atos, o contato formal com o público e a padronização dos procedimentos administrativos são elementos fundamentais na garantia de imparcialidade. Assim, a antecipação do que poderia ser a decisão, divulgada no procedimento de audiência pública como plataforma a ser defendida e implementada, exerce a função de controle e de submissão ao contraditório, além de propiciar a coleta de informações sobre interesses relevantes e contrastantes que irão enformar o processo de ponderação, próprio a qualquer decisão que admita a discricionariedade, assim como resulta na identificação de interesses irrelevantes para o caso concreto. Tal forma de atuar, embora não elimine a participação oculta e as pressões externas, nem esteja infensa às adversidades próprias da ponderação de interesses conflitantes, tem a característica de trazer publicidade às questões, conferindo um caráter mais democrático ao procedimento administrativo, na medida e que permite o controle dos aspectos materiais da decisão, pois, condiciona a fundamentação formal do ato decisório, organizando a racionalidade 
expositiva e a aferição dos liames de imparcialidade no procedimento administrativo e, em particular, no ato decisório, pela averiguação da compatibilidade com os atos externados ao longo do processo.

\section{Biografia do Autor}

\section{David Duarte, Universidade de Lisboa (Lisboa, Portugal)}

Doutor em Direito Administrativo. Professor da Universidade de Lisboa.

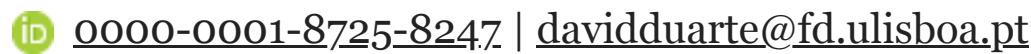

\section{Referências}

Aarnio, Aulis - 1983. Sobre la Racionalidad de la Racionalidad. Algunas Observaciones Sobre la Justificación Jurídica. Anales De La Cátedra Francisco Suarez. 23/24. 1.

Adamovich, Ludwig / Funk, Bernd-Christian - 1984. Allgemeines Verwaltungsrecht. 2 Auflage. Wien: Springer.

Allegretti, Umberto. Reflexos procedimentais do princípio da imparcialidade administrativa

Allegretti, Umberto - 1984. Pubblica Amministrazione e Ordinamento Democratico. Il Foro Italiano. 204.

Allegretti, Umberto - 1965. L'Imparzialità Amministrativa. Padova: Cedam.

Alexy, Robert - 1986. Ermessensfehler. Juristen Zeitung. 701.

Amaral, Diogo Freitas do - 1992. Fases do Procedimento Decisório Do 10 Grau. Direito e Justiça. VI. 25.

Amaral, Diogo Freitas do - 1992. O Novo Código do Procedimento Administrativo. O Código Do Procedimento Administrativo. Lisboa: INA. 21.

Amaral, Diogo Freitas do - 1989. Direito Administrativo. III. Lisboa (policopiado). Amiot, Michel

Amaral, Diogo Freitas do - 1972. Le Phénomène Consultatif. La Consultation Dans 1 Administration Contemporaine. Paris: Cujas. 39.

Andrade, José Carlos Vieira de - 1991. O Dever da Fundamentação Expressa de Actos Administrativos. Coimbra: Almedina.

Andreani, Antonio - 1993. Idee Per un Saggio Sulla Motivazione Obbligatoria dei Provvedimenti Amministrativi. Diritto Processuale Amministrativo. 1.

Badura, Peter - 1992. Das Verwaltungsverfahren. Allgemeines Verwaltungsrecht. 9 Auflage. Berlin: De Gruyter. 423. 
Barone, Giuseppe - 1986. Aspetti dell'Attività Interna della Pubblica Amministrazione. Milano: Giuffrè.

Bassi, Franco - 1991. Lezioni Di Diritto Amministrativo. 3a Edizione. Milano: Giuffrè.

Benvenuti, Feliciano - 1959. Appunti di Diritto Amministrativo. 4a Edizione. Padova: Cedam.

Bergonzini, Gherardo - 1975. L'Attività del Privato nel Procedimento Amministrativo. Padova: Cedam.

Bonnefoy, Jean-Louis - 1972. Les Groupes de Pression. La Consultation Dans 1 'Administration Contemporaine. Paris: Cujas. 197.

Bortolotti, Dario - 1984. Attività Preparatoria e Funzione Amministrativa. Milano: Giuffrè.

Cane, Peter - Reflexos procedimentais do princípio da imparcialidade administrativa

Cane, Peter - 1992. An Introduction to Administrative Law. 2a Edition. Oxford: Oxford University Press.

Canotilho, José Joaquim Gomes - 1990. Procedimento Administrativo e Defesa do Ambiente. Revista De Legislação e Jurisprudência. 123. 3794 (134). 3795 (168). 3798 (261). 3799 (289). 3800 (325).3802 (7).

Cardi, Enzo - 1989. La Ponderazione di Interessi nei Procedimenti di Pianificazione Urbanistica. Il Foro Italiano. 864.

Cardi, Enzo - 1983. La Manifestazione di Interessi nei Procedimenti Amministrativi. Rimini: Maggioli. Cassagne, Juan Carlos

Cardi, Enzo - 1991. Derecho Administrativo. II. 3a Edición. Buenos Aires: Abeledo Perrot. Chevallier, Jacques

Cardi, Enzo - 1988. Le Mythe de la Transparence Administrative. Information et Transparence Administratives. Paris: CURAPP. 239.

Claro, João Martins - 1992. A Marcha do Procedimento. O Código do Procedimento Administrativo. Lisboa: INA. 61.

Cognetti, Stefano - 1987. La Tutela delle Situazioni Soggettive tra Procedimento e Processo. Perugia: Edizione Scientifiche Italiane.

Collaço, Isabel Magalhães - 1949. A Legitimidade No Acto Jurídico. Boletim do Ministério da Justiça. 10. 20. Correia, José Manuel Sérvulo

Collaço, Isabel Magalhães - 1994. O Direito à Informação e os Direitos de Participação dos Particulares no Procedimento e, em Especial, na Formação da Decisão Administrativa. Legislação, Cadernos De Ciência Da Legislação. 9/10. 133. 
Collaço, Isabel Magalhães - 1982. Noções De Direito Administrativo. Lisboa: Danúbio.

Craig, Paul - 1989. Administrative Law. 2 Edition. Oxford: Oxford University Press.

Cunha, Paulo Ferreira da -1987. O Procedimento Administrativo. Coimbra: Almedina.

D'Alessandro, Simonetta - 1988. Obbligo di Motivazione del Provvedimento

Amministrativo e Interesse Sostanziale del Ricorrente. Il Foro Amministrativo. 3722.

Dechsling, Rainer - Reflexos procedimentais do princípio da imparcialidade administrativa

Dechsling, Rainer - - 1985. Rechtsschutz und Begründungspflicht. Die Öffentliche Verwaltung. 714. Dolzer, Rudolf

Dechsling, Rainer - - 1985. Zum Begründungsgebot im Geltenden Verwaltungsrecht. Die Öffentliche Verwaltung. 9.

Gellhorn, Ernest / Levin, Ronald - 1990. Administrative Law And Process. 3 Edition. St. Paul: West.

Giannini, Massimo - 1993. Diritto Amministrativo. 3a Edizione. I. II. Milano: Giuffrè.

Giannini, Massimo - 1986. Motivazione dell'Atto Amministrativo. Enciclopedia del Diritto. XXVII. Milano: Giuffrè. 257.

Glaeser, Walter Schmitt - 1984. Die Position Der Bürger als Beteiligte im Entscheidungsverfahren Gestaltender Verwaltung. Verfahren als Staats- und Verwaltungsrechtliche Kategorie. Heidelberg: Decker \& Müller. 35.

Gordillo, Agustin - 1984. Teoría General del Derecho Administrativo. Madrid: IEAL.

Gubelt, Manfred - 1982. Begründungsfehler des Bebauungsplans. Neue Zeitschrift für Verwaltungsrecht. 176.

Hoppe, Werner - 1994. Das Abwägungsgebot in der Novellierung des Baugesetzbuches. Deutsches Verwaltungsblatt. 1033.

Hoppe, Werner - 1970. Die Schranken der Planerischen Gestaltungsfreiheit. Baurecht. I.15.

Horak, Franz - 1974. Zur Rechtstheoretischen Problematik der Juristischen Begründung von Entscheidungen. Die Entscheidungsbegründung im Europäischen Verfahrensrechten und im Verfahren vor Internationalen Gerichten, Wien: Springer. 1.

Hufen, Friedhelm - 1991. Fehler im Verwaltungsverfahren. 2 Auflage. Baden-Baden: Nomos.

Iannota, Raffaele - 1975. La Motivazione Come Modo di Attuazione del Principio di Imparzialità Amministrativa, Il Foro Amministrativo. 525. 
Irelli, Vicenzo Cerulli - 1985. Pianificazione Urbanistica e Interessi Differenziati. Rivista Trimestrale di Diritto Pubblico. 386.

Isaac, Guy - 1968. La Procédure Administrative Non Contentieuse. Paris: LGDJ.

Jowell, Jeffrey - Reflexos procedimentais do princípio da imparcialidade administrativa

Jowell, Jeffrey - 1968. The Limits Of Public Hearing As A Tool Of Urban Planning. Administrative Law Review. 21. 123.

Kopp, Ferdinand - 1977. Der Beteiligtenbegriff des Verwaltungsverfahrensrechts. Festschrift zum 50-Jährigen Bestehen Des Richard Boorberg Verlags, München: Richard Boorberg Verlag. 159.

Koenig, Christian - 1992. Der Begründungszwang in Mehrpoligen Verwaltungsrechts Verhältnissen am Beispiel Umweltrelevanter Entscheidungen. Archiv des Öffentlichen Rechts. 513.

Korbmacher, Günter - 1982. Eigentums- Undentschädigungsrechtlich Bedeutsame Entscheidungen in der Fachplanerischen Abwägung. Die Öffentliche Verwaltung. 517.

Langrod, George - 1972. L'Administration Consultative. La Consultation dans 1 'Administration Contemporaine, Paris: Cujas. 60.

Mantini, Pierluigi - 1990. Associazioni Ambientaliste e Interessi Diffusi nel Procedimento Amministrativo. Padova: Cedam.

Masucci, Alfonso - 1983. Garanzie del Cittadino di Fronte alla Pubblica Amministrazione. Democrazia e Diritto. 6. 113 .

Maurer, Hartmut - 1992. Allgemeines Verwaltungsrecht. 8 Auflage. München: Beck. Melo, António Barbosa de - 1987. Direito Administrativo II. Coimbra (policopiado). Moor, Pierre - 1991. Droit Administratif. II. Berne: Staempfli.- 1992. Droit Administratif. III. Berne: Staempfli.

Oliveira, Mário Esteves de - 1980. Direito Administrativo. Coimbra: Almedina.

Oliveira, Esteves de / Gonçalves, Pedro / Amorim, Pacheco - 1993. Código Do Procedimento Administrativo Comentado. Coimbra: Almedina.

Ossenbühl, Fritz - 1982. Verwaltungsverfahren zwischen Verwaltungseffizienz und Rechtsschutzauftrag. Neue Zeitschrift für Verwaltungsrecht. 465.

Otero, Paulo - Reflexos procedimentais do princípio da imparcialidade administrativa Otero, Paulo - 1992. Conceito e Fundamento da Hierarquia Administrativa. Coimbra: Almedina. Pacteau, Bernard 
Otero, Paulo - 1971. Motivation des Actes Administratifs. Recueil Dalloz Sirey. 344.

Paleologo, Giovanni - 1991. La Legge 1990 N. 241: Procedimenti Amministrativi ed Accesso ai Documenti dell' Amministrazione. Diritto Processuale Amministrativo. 8.

Peczenik, Aleksander - 1985. On The Rational And Moral Basis Of Legal Justification. Archiv für Rechtsphilosophie und Sozialphilosophie. 2. 263.

Pierce Jr., Richard / Shapiro, Sidney / Verkuil, Paul - 1992. Administrative Law And Process. 2 Edition. New York: Foundation Press.

Piraino, Salvatore - 1990. La Funzione Amministrativa fra Discrezionalità e Arbitrio. Milano: Giuffrè.

Pubusa, Andrea - 1988. Procedimento Amministrativo e Interessi Sociali. Torino: Giappichelli.

Pugliese, Francesco Paolo - 1988. Il Contradittorio nel Procedimento. Il Procedimento Amministrativo fra Riforme Legislative e Trasformazioni dell'Amministrazione. Milano: Giuffrè. 25 .

Ramsauer, Ulrich - 1981. Abwägungskontrolle und Subjektiver Rechtsschutz im Planfestellungsverfahren. Die Öffentliche Verwaltung. 37.

Rivalta, Maria - 1960. La Motivazione degli Atti Amministrativi In Relazione al Pubblico e Privato Interese. Milano: Giuffrè.

Romano-Tassone, Antonio - 1987. Motivazione dei Provvedimenti Amministrativi e Sindicato di Legittimità. Milano: Giuffrè.

Roy, Bernard - 1985. Méthodologie Multicritère d'Aide à la Décision. Paris: Economica.

Sanchez Moron, Miguel - 1980. La Participación del Ciudadano en la Administración Pública. Madrid: Civitas. Sandulli, Aldo

Sanchez Moron, Miguel - 1982. Manuale di Diritto Amministrativo. 13 Edizione. I. II. Napoli: Jovene.

Sanchez Moron, Miguel - 1964. Il Procedimento Amministrativo. Milano: Giuffrè.

Schick, Walter - Reflexos procedimentais do princípio da imparcialidade administrativa

Schick, Walter - 1971. Notwendigkeit und Funktion der Begründung bei Verwaltungsakten. Juristische Schulung. 1. 1.

Schmidt-Aßmann, Eberhard - 1993. El Procedimiento Administrativo entre el Principio del Estado de Derecho y el Principio Democratico. El Procedimiento Administrativo en el Derecho Comparado, Madrid: Civitas. 317. 
Schmidt-Aßmann, Eberhard - 1984. Der Verfahrensgedanke in der Dogmatik des Öffentlichen Rechts. Verfahren als Staats- und Verwaltungsrechtliche Kategorie, Heidelberg: Decker \& Müller. 1.

Schmidt, Walter - 1982. Einführung in die Probleme des Verwaltungsrechts. München: Beck.

Schwartz, Bernard - 1991. Administrative Law. 3 Edition. Boston: Little Brown Company.

Sepe, Onorato - 1975. L'Efficienza nell'Azione Amministrativa. Milano: Giuffrè.

Sfez, Lucien - 1988. La Décision. 2 Edition. Paris: PUF.

Siwek-Pouydesseau, Jeanne - 1972. Consultation et Participation. La Consultation dans 1 Administration Contemporaine, Paris: Cujas. 223.

Soares, Rogério Eberhard - 1978. Direito Administrativo. Coimbra (policopiado).

Steinberg, Rudolf - 1982. Komplexe Verwaltungsverfahren zwischen Verwaltungseffizienz und Rechtsschutzauftrag. Die Öffentliche Verwaltung. 619.

Tedeschini, Federico - 1986. Il Procedimento Amministrativo. Enciclopedia Del Diritto. XXXV. Milano: Giuffrè. 872.

Ule, Carl Hermann / Laubinger, Hans-Werner - 1992. Verwaltungsverfahrensrecht. 3 Auflage. Köln: Heymanns Verlag.

Voucko, Manfred - 1967. Die Pflicht Zur Begründung von Verwaltungsakten. Frankfurt: Universität Frankfurt am Main.

Wroblewsky, Jerzy - 1989. Conceptions Of Justification In Legal Discourse. Rivista Internazionale di Filosofia del Diritto. 678.

\section{Publicado}

2021-12-15

\section{Como Citar}

DUARTE, D. Reflexos procedimentais do princípio da imparcialidade administrativa: Administrative reflections of the administrative impartiality principle . Revista de Direito Administrativo e Infraestrutura | RDAI, São Paulo: Thomson Reuters Livraria RT, v. 5, n. 19, p. 235-298, 2021. DOI: 10.48143/rdai.19.dd. Disponível em: https://rdai.com.br/index.php/rdai/article/view/427. Acesso em: 7 fev. 2022.

\section{Edição}


Seção

Doutrina Estrangeira

\section{Licença}

\section{(c) $(1) \Theta \Theta$}

Este trabalho está licenciado sob uma licença Creative Commons Attribution-

NonCommercial-NoDerivatives 4.0 International License.

(CC BY-NC-ND).

Este é um resumo (e não um substituto) da licença

$\underline{\text { Regras para publicaçãão }}$

Direitrizes Editoriais

Direitos e Deveres

Errata e Retratação

Preservação e Plagiarismo

Revisão e Avaliação 
